Original Paper

\title{
Performance and Flow Condition of Contra-rotating Small-sized Axial Fan at Partial Flow Rate
}

\author{
Toru Shigemitsu ${ }^{1}$, Junichiro Fukutomi ${ }^{1}$, Yuki Okabe $^{2}$ and Kazuhiro Iuchi ${ }^{2}$ \\ ${ }^{1}$ Institute of Technology and Science, The University of Tokushima \\ 2-1 Minamijosanjima-cho, Tokushima-city, 770-8506, Japan, t-shige@me.tokushima-u.ac.jp \\ ${ }^{2}$ Graduate School of Advanced Technology and Science, The University of Tokushima \\ 2-1 Minamijosanjima-cho, Tokushima-city, 770-8506, Japan
}

\begin{abstract}
Small-sized axial fans are used as air cooler for electric equipments. But there is a strong demand for higher power of fans according to the increase of quantity of heat from electric devices. Therefore, higher rotational speed design is conducted, although, it causes the deterioration of efficiency and the increase of noise. Then the adoption of contrarotating rotors for the small-sized axial fan is proposed for the improvement of performance. In the present paper, the performance curves of the contra-rotating small-sized axial fan with $100 \mathrm{~mm}$ diameter are shown and the velocity distributions at a partial flow rate at the inlet and the outlet of each front and rear rotor are clarified with experimental results. Furthermore, the flow conditions between front and rear rotors of the contra-rotating small-sized axial fan are investigated by numerical analysis results and causes of the performance deterioration of the contra-rotating small-sized axial fan at the partial flow rate is discussed.
\end{abstract}

Keywords: Small-sized axial fan, Contra-rotating rotors, Performance, Internal flow, Partial flow rate, Numerical analysis

\section{Introduction}

Because of spread of cloud computing, establishment of ubiquitous networking society and the increase in the rate of electric parts in machines, power consumption in data centers, IT devices and machines has been increasing significantly. In the view of the issue of global warming and energy savings, there is a strong demand for the reduction of power consumption in above facilities and equipments[1]. Electrical power used for the cooling of the IT devices for data centers is huge the same as that used for the IT devices itself in data centers. Small-sized axial fans are used as air coolers for electric equipments i.e. laptop, desk top computers and servers. There is a strong demand for higher power of fans according to the increase of quantity of heat from electric devices. However, the increase of the power by the increase of the fan diameter is restricted because of the limitation of the space. Therefore, higher rotational speed design is conducted, although, it causes the deterioration of the efficiency and the increase of noise. On the other hand, lower rotational speed design[2] and advantages on the performance of the contra-rotating fans and pumps are verified by experimental results[3],[4]. Then the adoption of contra-rotating rotors for small-sized fans is proposed for the improvement of the performance. In the case of contra-rotating rotors, the axial space becomes larger than conventional small-sized axial fans. However, it is adequate choice to apply the contra-rotating rotors for small sized-fans because the axial space can be ensured in electrical devices as compared to that of the radial space.

In the case of contra-rotating rotors, it is necessary to design rear rotor considering the unsteady circumferential velocity distributions at the outlet of the front rotor[5]. Further, it is important to clarify the influence of the wake from the front rotor to the rear rotor on the performance and pressure interaction between front and rear rotors[6]. On the other hand, the conventional design method and the theory for the turbo machinery should be modified for small-sized axial fans because small-sized axial fans applied to electrical devices belong to extremely small size field in the turbo machinery[7]. Therefore, there is the strong demand to establish the design method for small-sized axial fans. Furthermore, the small-sized axial fan would be used at part load operating point which means partial flow rate, therefore, the improvement of the performance at partial flow rate is also important.

In the present paper, the performance curves of the contra-rotating small-sized axial fan with 100mm diameter are shown and the internal flow conditions at a partial flow rate are clarified by experimental results. Furthermore, the relations between the performance and flow conditions were discussed by the experimental and numerical results and an operating method to improve the performance of contra-rotating small-sized axial fan at the partial flow rate is considered.

Received August 2 2010; revised September 13 2010; accepted for publication October 5 2010: Review conducted by Prof. Yutaka Ota. (Paper number O10020J)

Corresponding author: Toru Shigemitsu, Associate Professor, t-shige@me.tokushima-u.ac.jp 


\section{Experimental Apparatus and Methods}

The rotor and the primary dimensions of a conventional axial fan(Rtype) and a contra-rotating axial fan(RRtype) are shown in Fig. 1 and Table 1 respectively. The hub tip ratio $D_{\mathrm{h}} / D_{\mathrm{t}}=45 \mathrm{~mm} / 98 \mathrm{~mm}$ and the designed flow rate was $Q_{\mathrm{d}}=0.016 \mathrm{~m}^{3} / \mathrm{s}$ for both types and fan static pressure at the design point was $\Delta P_{\mathrm{dR}}=13.7 \mathrm{~Pa}$ for Rtype and $\Delta P_{\mathrm{dRR}}=14.7 \mathrm{~Pa}$ for RRtype with the same fan static pressure of each front and rear rotor. The rotational speed of Rtype was $N=3000 \mathrm{~min}^{-1}$. On the other hand, the rotational speed of front and rear rotors of RRtype was $N_{f}=N_{r}=1780 \mathrm{~min}^{-1}$ in order to make the specific speed of each rotor for RRtype almost the same as Rtype. In this research, an aerofoil blade was used because there was a report which implied an advantage of the aerofoil blade for the small-sized axial fan[8], however a circular-arc blade was generally used for small-sized axial fans. RRtype rotor used for the experiment was changed a little from the rotor for the numerical analysis in the blade thickness, because the thickness for the numerical analysis rotor was thin and the lack of the strength for using it for the experiment was worried. Both of the rotors were designed to achieve the same performance at design condition. In this paper, the flow conditions at partial flow rate $Q=0.0096 \mathrm{~m}^{3} / \mathrm{s}$ were focused. The influence of the difference of the rotor between the experiment and the numerical analysis on flow conditions at partial flow rate $Q=0.0096 \mathrm{~m}^{3} / \mathrm{s}$ could be small because the thickness of the rotor was mainly changed. Figure 2 shows the schematic diagram of the experimental apparatus for RRtype. The experimental apparatus was designed based on the Japanese Industrial Standard and the air blown in the test section passed the rotor, chamber, measurement duct and booster fan and blew out in the ambient atmosphere. The fan static pressure $(\triangle P)$ was measured by the pressure difference between static holes downstream of the rotor installed at the chamber and ambient air. Fan static pressure of each front and rear rotor was also measured for RRtype to investigate pressure curves of each front and rear rotor in wide flow rates range. Further, the rotational speed was controlled by the servo motor and the flow rates were measured by the orifice meter set at the measurement duct. The pressure curves from the cutoff flow rate to the large flow rate were investigated in the experiment with the constant rotational speed $N_{\mathrm{f}}=N_{\mathrm{r}}=1780 \mathrm{~min}^{-1}$ for RRtype and $N=3000 \mathrm{~min}^{-1}$ for Rtype. The internal flow measurements at the inlet and the outlet of each rotor were conducted with a one-hole cylindrical pitot tube having an outer diameter of 2.0mm. This tube was used as the substitution of a three-hole pitot tube by rotating it by $\pm 30^{\circ}$. The measurements in axial direction were conducted from $5 \mathrm{~mm}$ upstream of the leading edge of the front rotor at the hub to 4 other axial upstream positions by interval of $10 \mathrm{~mm}$ at the inlet of the front rotor, at $5 \mathrm{~mm}$ downstream of the trailing edge of the front rotor at the hub to 4 other axial downstream positions by interval of $5 \mathrm{~mm}$ at the outlet of the front rotor and at $6 \mathrm{~mm}$ downstream of the trailing edge of the rear rotor at the hub, from $40 \mathrm{~mm}$ downstream of the trailing edge of it to 6 other axial downstream positions by interval of $10 \mathrm{~mm}$ at the outlet of the rear rotor. Further, the measurements in radial direction were conducted from $r=28.5 \mathrm{~mm}$ to $r=49.5 \mathrm{~mm}$ by interval of $3 \mathrm{~mm}$ at $8 \mathrm{radial}$ positions. Therefore, the total of the measurements points were 144 points.

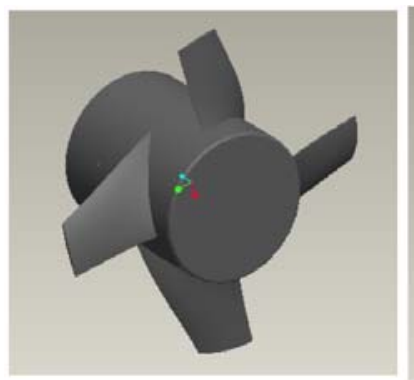

(a) Rtype

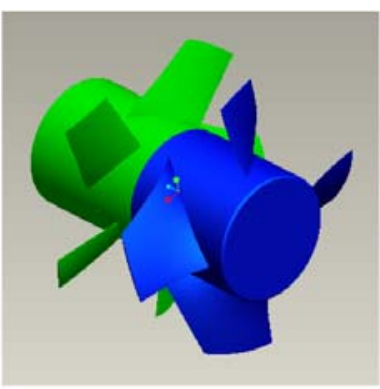

(b) RRtype

Fig. 1 Small-sized axial fan

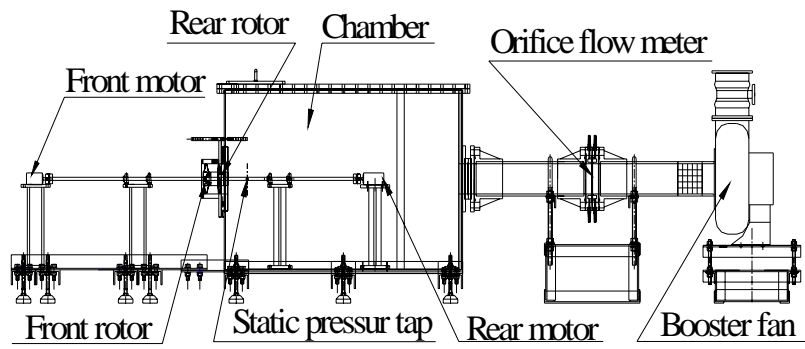

Fig. 2 Experimental apparatus

Table 1 Primary dimensions of R and RRtypes

\begin{tabular}{|c|c|c|c|c|}
\hline & & Hub & Mid & Tip \\
\hline \multirow{5}{*}{$\begin{array}{l}\text { Rotor } \\
\text { (Rtype) }\end{array}$} & Diameter $[\mathrm{mm}]$ & 45 & 72 & 98 \\
\hline & Blade Number & \multicolumn{3}{|c|}{4} \\
\hline & Blade Profile & \multicolumn{3}{|c|}{ NACA4412 } \\
\hline & Solidity & 0.908 & 0.361 & 0.208 \\
\hline & Stagger Angle & $59.84^{\circ}$ & $60.11^{\circ}$ & $74.87^{\circ}$ \\
\hline \multirow{4}{*}{$\begin{array}{l}\text { Front Rotor } \\
\text { (RRtype-exp.) }\end{array}$} & Blade Number & \multicolumn{3}{|c|}{4} \\
\hline & Blade Profile & \multicolumn{3}{|c|}{ NACA4409 } \\
\hline & Solidity & 1.196 & 0.496 & 0.29 \\
\hline & Stagger Angle & $44.67^{\circ}$ & $61.09^{\circ}$ & $68.15^{\circ}$ \\
\hline \multirow{4}{*}{$\begin{array}{c}\text { Rear Rotor } \\
\text { (RRtype-exp.) }\end{array}$} & Blade Number & \multicolumn{3}{|c|}{5} \\
\hline & Blade Profile & \multicolumn{3}{|c|}{ NACA4412 } \\
\hline & Solidity & 0.91 & 0.447 & 0.288 \\
\hline & Stagger Angle & $56.73^{\circ}$ & $64.54^{\circ}$ & $69.60^{\circ}$ \\
\hline \multirow{4}{*}{$\begin{array}{l}\text { Front Rotor } \\
\text { (RRtype-cal.) }\end{array}$} & Blade Number & \multicolumn{3}{|c|}{4} \\
\hline & Blade Profile & \multicolumn{3}{|c|}{ NACA4406 } \\
\hline & Solidity & 1.245 & 0.508 & 0.308 \\
\hline & Stagger Angle & $42.40^{\circ}$ & $60.11^{\circ}$ & $67.21^{\circ}$ \\
\hline \multirow{4}{*}{$\begin{array}{c}\text { Rear Rotor } \\
\text { (RRtype-cal.) }\end{array}$} & Blade Number & \multicolumn{3}{|c|}{5} \\
\hline & Blade Profile & \multicolumn{3}{|c|}{ NACA4409 } \\
\hline & Solidity & 0.91 & 0.447 & 0.288 \\
\hline & Stagger Angle & $55.92^{\circ}$ & $63.91^{\circ}$ & $68.87^{\circ}$ \\
\hline
\end{tabular}

\section{Numerical Analysis Conditions}

The commercial software ANSYS-Fluent was used to investigate the flow condition which couldn't be measured by the experiment. In the numerical analysis, the numerical model which was almost the same with the experimental apparatus was used and three dimensional steady numerical analysis was conducted. The numerical grids used for the numerical analysis are shown in Fig.3. The numerical domains comprised the inlet, rotor, chamber and outlet duct regions. The numbers of numerical grids for the inlet, chamber and outlet duct region were the same for both rotor types. The numerical grid numbers were 218,039 for the inlet 
region, 667,135 for the chamber region and 39,875 for the outlet duct region. The numerical grid numbers for the rotor region were 1,521,481 in case of Rtype and 3,613,381 in case of RRtype. The number of nodes along the front and the rear rotor blades at the hub were 150 nodes and 80 nodes. The number of nodes of blade-to-blade of the front and the rear rotors were 35 nodes and 30 nodes. The number of nodes from hub to tip of the front and the rear rotors were 110 nodes and 100 nodes. The tip clearance was kept $1 \mathrm{~mm}$ as the same with the experimental apparatus in the numerical analysis and the number of nodes from the blade tip to the casing was 7 nodes. The numerical grids over 150,000 were ensured at the tip clearance. The $\mathrm{y}^{+}$was 15 near the hub of the rotor for both Rtype and RRtype. At the inlet boundary, the uniform velocity was given and the constant pressure was given as the outlet boundary condition. The coupling between the front and the rear rotors was accomplished by the frozen rotor method with multiple reference frames. The standard wall function and $k-\omega$ turbulence model was used. The numerical flow analysis was conducted at the 6 different flow rates from $0.0096 \mathrm{~m}^{3} / \mathrm{s}$ to $0.0192 \mathrm{~m}^{3} / \mathrm{s}$.

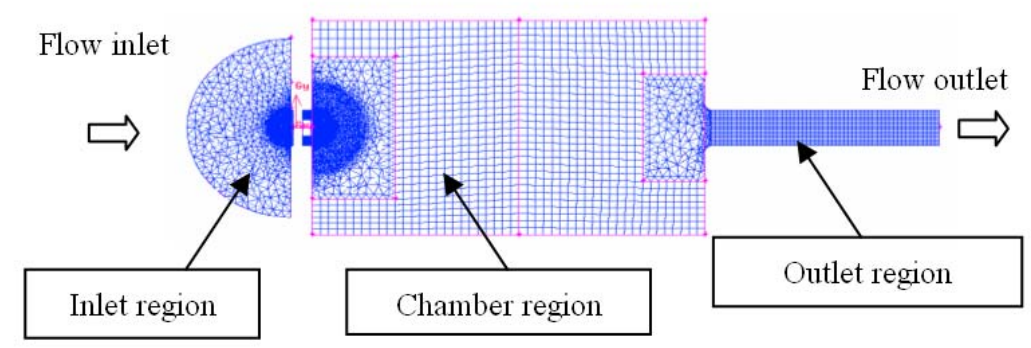

Fig. 3 Numerical analysis grids

\section{Performance Curves of Rtype and RRtype}

Figure 4(a) shows fan static pressure curves of Rtype and RR type obtained by the experiment and fan static pressure curves of each front and rear rotor for RRtype are shown in Fig4(b). A shaft power and an efficiency of Rtype and RRtype obtained by the numerical analysis are shown in Fig.5. In Fig.4(a), the fan static pressure curves obtained by the numerical analysis are also shown to compare with the experimental results. It could be found that the fan pressure increased according to the decrease of the flow rates and the pressure curves showed the stable negative curve from the experimental results of both Rtype and RRtype. Further, numerical results represented the qualitative tendency of the experimental results. The fan static pressure of Rtype and RRtype were $\triangle P=7.5 \mathrm{~Pa}$ and $\triangle P=10.0 \mathrm{~Pa}$ at the designed flow rate $Q_{\mathrm{d}}=0.016 \mathrm{~m}^{3} / \mathrm{s}$. The fan pressure of RRtype was higher than that of Rtype in wide flow rate range from $Q=0.0064 \mathrm{~m}^{3} / \mathrm{s}$ to $Q=0.0176 \mathrm{~m}^{3} / \mathrm{s}$ and an advantage of RRtype could be confirmed that high fan static pressure could be obtained for RRtype. However, the fan static pressure of RRtype was lower than that of Rtype near shut off flow rate and over flow rate $0.0192 \mathrm{~m}^{3} / \mathrm{s}<Q$. Further, the fan pressures of Rtype and RRtype at the designed flow rate were lower than designed fan pressure $\Delta P_{\mathrm{dR}}=13.7 \mathrm{~Pa}$ and $\Delta P_{\mathrm{dRR}}=14.7 \mathrm{~Pa}$. The slope of fan pressure curve for RRtype changed at $Q=0.0128 \mathrm{~m}^{3} / \mathrm{s}$ and $Q=0.0096 \mathrm{~m}^{3} / \mathrm{s}$. Focused on fan static pressure curves of each front and rear rotor in Fig.4(b), the fan static pressure curve of the front rotor showed the negative curve. On the other hand, the fan static pressure curve of the rear rotor showed a gentle negative slope curve from $Q=0.01$ to $Q=0.0192 \mathrm{~m}^{3} / \mathrm{s}$ and the curve became flat in flow rates range $Q<0.01 \mathrm{~m}^{3} / \mathrm{s}$. Therefore, the change of the fan pressure curve slope at $Q=0.0128 \mathrm{~m}^{3} / \mathrm{s}$ was caused by the decrease of the fan static pressure of the rear rotor. The efficiency of RRtype at the designed flow rate $Q_{\mathrm{d}}=0.016 \mathrm{~m}^{3} / \mathrm{s}$ was $(\eta=44.4 \%$ ) higher than that of Rtype ( $\eta=34.8 \%$ ). Furthermore, the efficiency of RRtype was higher than that of Rtype in all flow rates, where numerical analysis was conducted. On that point, the advantages

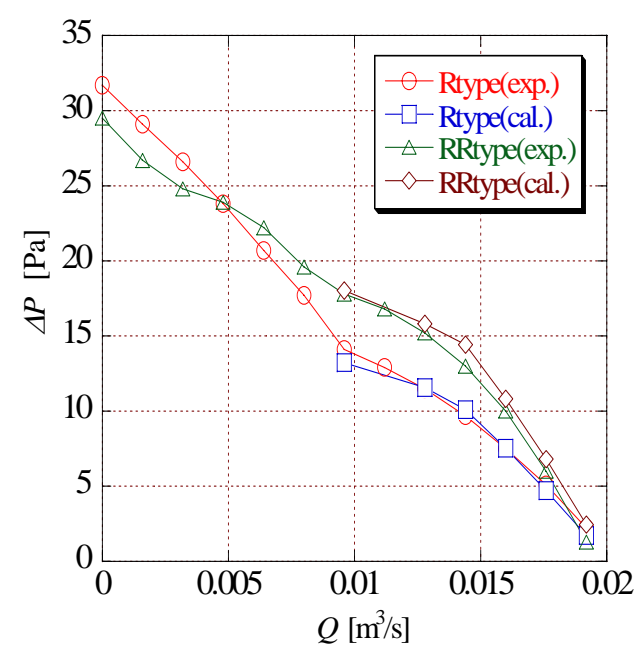

(a) Fan static pressure curves of R and RRtypes

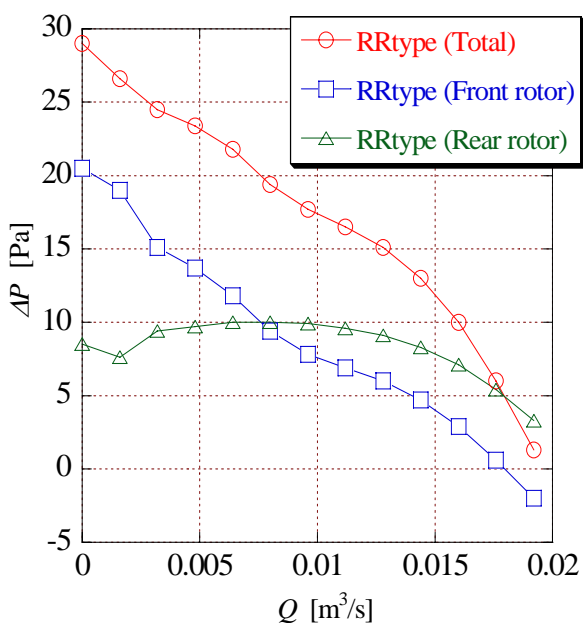

(b) Fan static pressure of each front and rear rotor

Fig. 4 Fan static pressure curves of of R and RRtypes

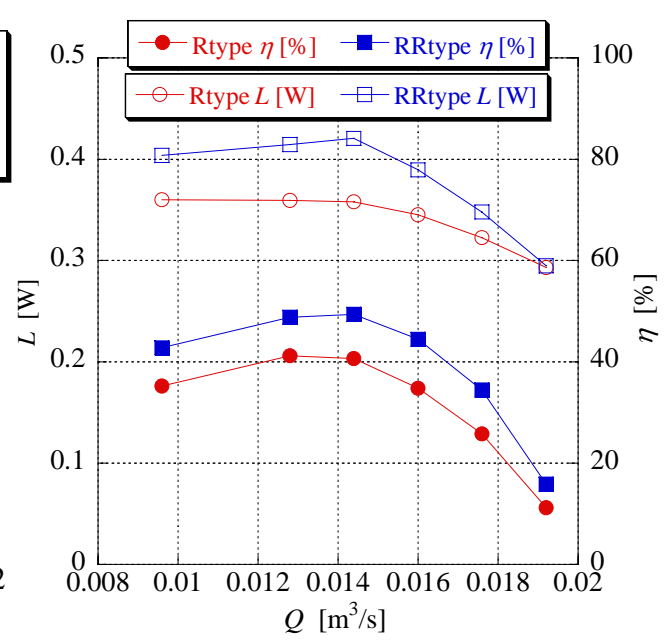

Fig. 5 Shaft power and efficiency curves of $\mathrm{R}$ and RRtypes 
of the adoption of contra-rotating rotors for small-sized fan were confirmed. The performance of RRtype around the designed flow rate was higher than that of Rtype, although, vice versa near shut-off flow rate and large flow rate. Small-sized axial fan could be used at partial flow rates and they could achieve the high performance in wide flow rate range. Then, the flow conditions at partial flow rate $Q=0.0096 \mathrm{~m}^{3} / \mathrm{s}$, where the slope of the fan static pressure changed and which was the smallest flow rate numerical analysis conducted, was investigated by experiment and numerical analysis.

\section{Flow Conditions at Partial Flow Rate}

\subsection{Flow Conditions at The Inlet of The Front Rotor}

It was important to investigate the internal flow condition in order to get better performance of RRtype. Then, the internal flow conditions were investigated by the experiment using a pitot tube and the numerical flow analysis. Figures 6(a),(b)and (c) show the axial velocity, the circumferential velocity and total pressure distributions obtained by the experiment at partial flow rate $Q=0.0096 \mathrm{~m}^{3} / \mathrm{s}$ in radial direction at the inlet of the front rotor of RRtype respectively. The vertical axis is non-dimensional radius divided by the radius at the casing; $r / r_{\mathrm{c}}=0.45$ and $r / r_{\mathrm{c}}=1.0$ correspond the hub and the casing. Further, the circumferential velocity $V_{\mathrm{t}}$ is a positive in the direction of the front rotor rotation. It was found from Fig.6(a) that the axial velocity increased gradually closing to the inlet of the front rotor and a back flow occurred near the tip of the front rotor at the $5 \mathrm{~mm}$ upstream of the front rotor inlet. On the other hand, focused on the circumferential velocity in Fig.6(b), the circumferential velocity was almost $V_{\mathrm{t}}=0$ until $15 \mathrm{~mm}$ upstream of the front rotor inlet and the circumferential velocity increased from the radial mid position to the tip of the front rotor at $5 \mathrm{~mm}$ upstream of the front rotor. It was observed that the total pressure was almost $P_{\mathrm{t}}=0$ until $15 \mathrm{~mm}$ upstream of the front rotor and the total pressure increased near the tip of the front rotor at $5 \mathrm{~mm}$ upstream of the front rotor. The increase of the total pressure near the tip of the front rotor was caused by the back flow with the circumferential velocity given by the front rotor. Figures 7(a) and (b) show the relative velocity vectors around the blade at the radial mid position $\left(r / r_{\mathrm{c}}=0.75\right)$ and at the tip of the front $\operatorname{rotor}\left(r / r_{\mathrm{c}}=0.98\right)$. Meridional velocity vectors near the tip of the front rotor are shown in Fig.8. The flow rate in Figs 7 and 8 is $Q=0.0096 \mathrm{~m}^{3} / \mathrm{s}$. The flow around the front rotor ran along the blade at $r / r_{\mathrm{c}}=0.75$ in Fig.7(a). However, the back flow occurred in

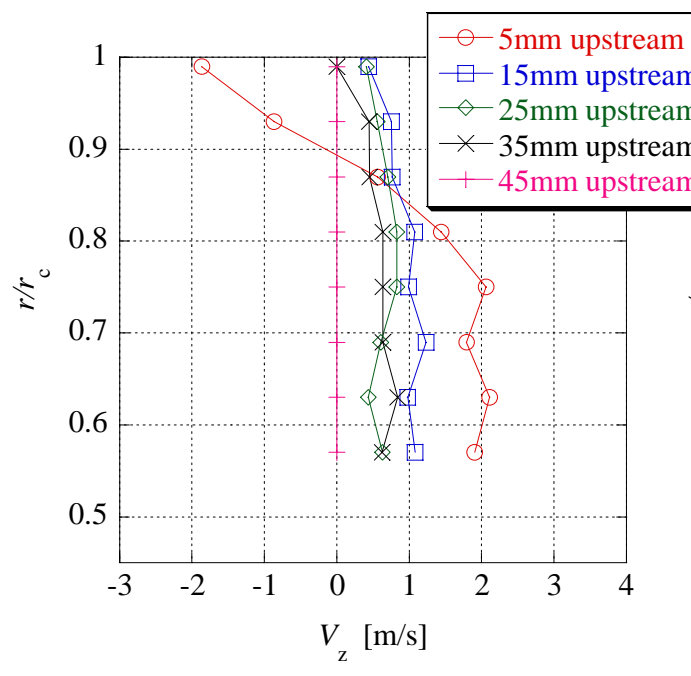

(a) Axial velocity distributions

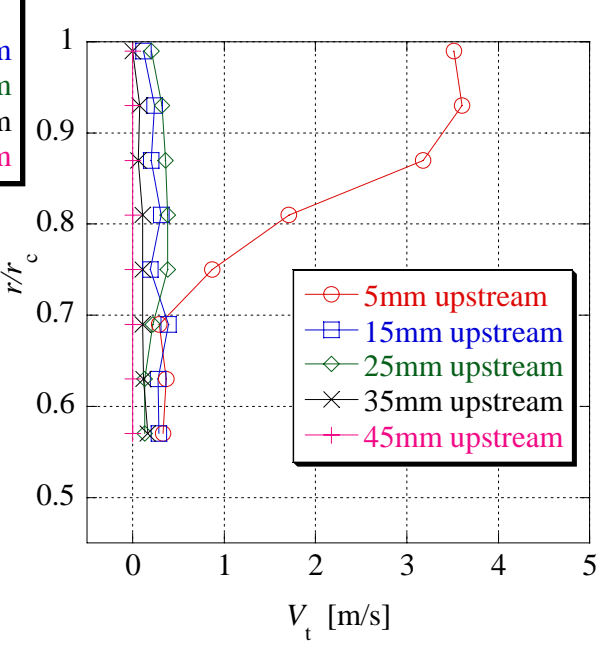

(b) Circumferential velocity distributions

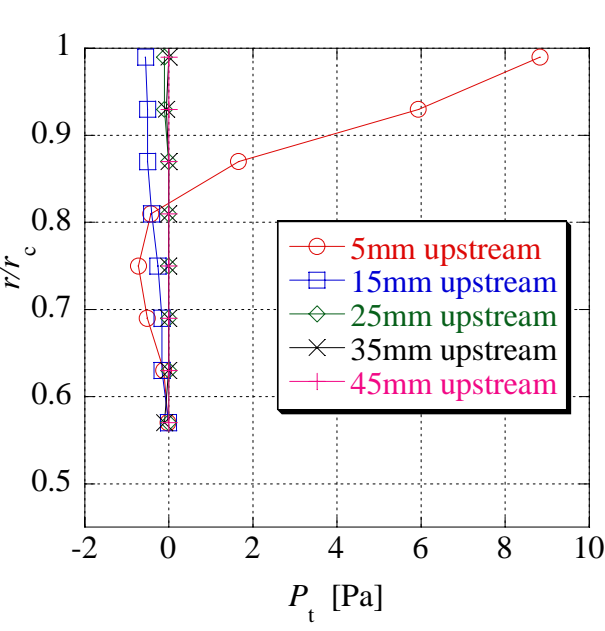

(c) Total pressure distributions

Fig. 6 Velocity and total pressure distributions at the front rotor inlet of RRtype $\left(Q=0.0096 \mathrm{~m}^{3} / \mathrm{s}\right)$

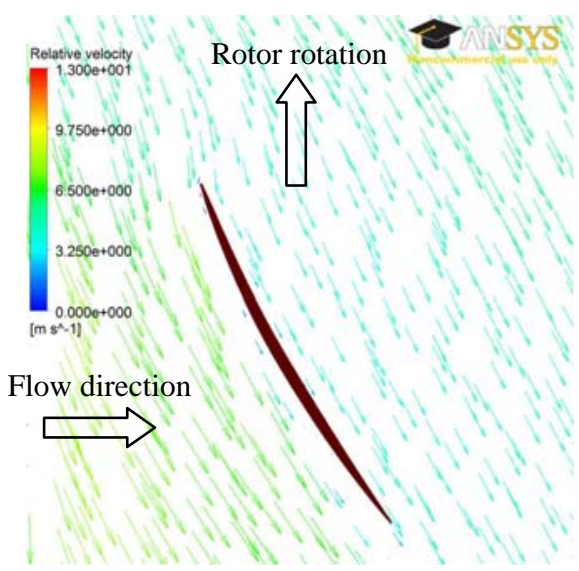

(a) $r / r_{\mathrm{c}}=0.75$

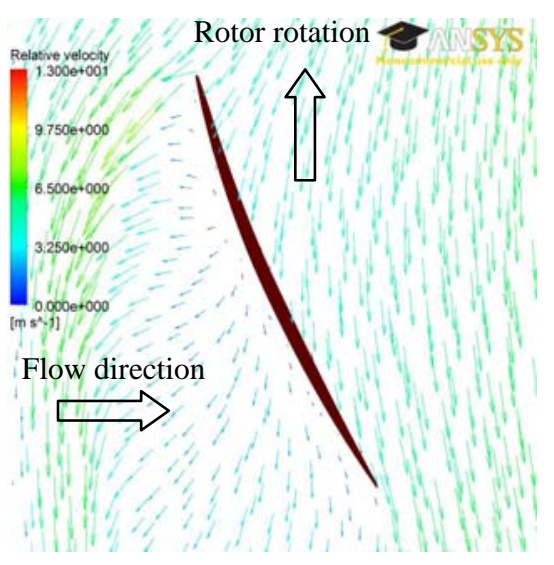

(b) $r / r_{\mathrm{c}}=0.98$

Fig. 7 Relative velocity vectors around the front rotor of RRtype $\left(Q=0.0096 \mathrm{~m}^{3} / \mathrm{s}\right)$

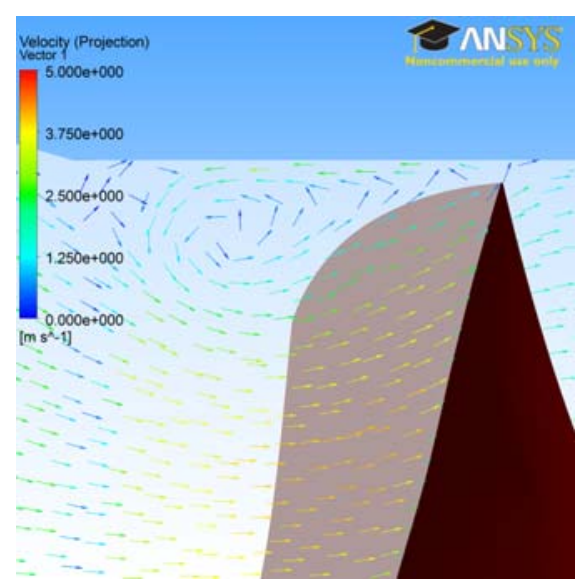

Fig. 8 Meridional velocity vectors near the tip of the front rotor of RRtype $\left(Q=0.0096 \mathrm{~m}^{3} / \mathrm{s}\right)$ 
wide region at the inlet of the blade at $r / r_{\mathrm{c}}=0.98$ and a leakage flow crossing the tip clearance from a pressure surface to a suction surface occurred in Fig.7(b). Focused on the flow conditions at the inlet of the rotor in Fig.8, the back flow with a vortex was observed near the tip of the front rotor and the flow in the front rotor inclined against hub side by a blockage effect of the back flow. This back flow could be caused by the wall stall near the casing and the leakage flow from the tip clearance.

\subsection{Flow Conditions Between The Front and The Rear Rotors}

It is important for contra-rotating small-sized axial fans to clarify the velocity distributions between the front and the rear rotors because the rear rotor should be designed considering the swirl flow from the front rotor. Further the fan static pressure of the rear rotor deteriorated at partial flow rate. This could be related to the flow conditions between the front and the rear rotors. Therefore, the flow conditions between the front and the rear rotors at $Q=0.0096 \mathrm{~m}^{3} / \mathrm{s}$ were investigated. Figures 9 (a) and (b) show the axial and the circumferential velocity distributions of RRtype obtained by the experiment between front and rear rotors at the partial flow rate $Q=0.0096 \mathrm{~m}^{3} / \mathrm{s}$ respectively. Values in a legend are distances of the measurement positions from the front rotor trailing edge at the hub. $25 \mathrm{~mm}$ in a legend corresponds $5 \mathrm{~mm}$ upstream of the leading edge of the rear rotor at the hub. The axial velocity decreased near tip region $r / r_{\mathrm{c}}>0.7$ between the front and the rear rotors. On the contrary, the axial velocity increased near the hub by the influence of the decrease of the axial velocity near the tip. The circumferential velocity near the tip region at $5 \mathrm{~mm}$ downstream of the front rotor was large and decreased drastically at 25mm downstream of it. Figures 10(a) and (b) show the static and the total pressure distributions of RRtype obtained by the experiment between front and rear rotors. The flow rate and the values in a legend are the same in Fig.9. The spanwise static pressure was the largest at the casing at $5 \mathrm{~mm}$ downstream of the front rotor and the position with the largest static pressure remained at the casing up to $25 \mathrm{~mm}$ downstream of it. On the other hand, the spanwise total pressure was largest near the casing at $5 \mathrm{~mm}$ downstream of the front rotor. However the total pressure near the casing decreased gradually in downstream direction and it was no more the largest total pressure in span at $15 \mathrm{~mm}$ downstream of the front rotor. The total pressure decrease related to the decrease of the circumferential velocity near the casing in Fig.9. The relative velocity around the rear rotor at $r / r_{\mathrm{c}}=0.98$ and the meridional velocity vectors near the tip of the rear rotor at $Q=0.0096 \mathrm{~m}^{3} / \mathrm{s}$ are shown in Figs 11 and 12 respectively. It was observed from Fig. 11 that a leakage flow crossing the tip clearance from the pressure surface to the suction surface were confirmed. Further, a back flow with a vortex also occurred at the inlet of the rear rotor tip. This back flow could contain a circumferential velocity in rear rotor rotational direction because of the work of the rear rotor. Therefore, the decrease of the circumferential velocity between front and rear rotors in Fig.9(b) would be caused by the back flow with the circumferential velocity in opposite direction of front rotor rotation near the inlet of the rear rotor tip. Eventually, the total pressure decrease at the inlet of the rear rotor tip was caused by the back flow at the inlet of the rear rotor and the back flow could be one of the reasons of decrease of the performance at partial flow rates. Figures 13(a) and (b) show the axial and the circumferential velocity distributions of RRtype obtained by the experiment between front and rear rotors at the designed

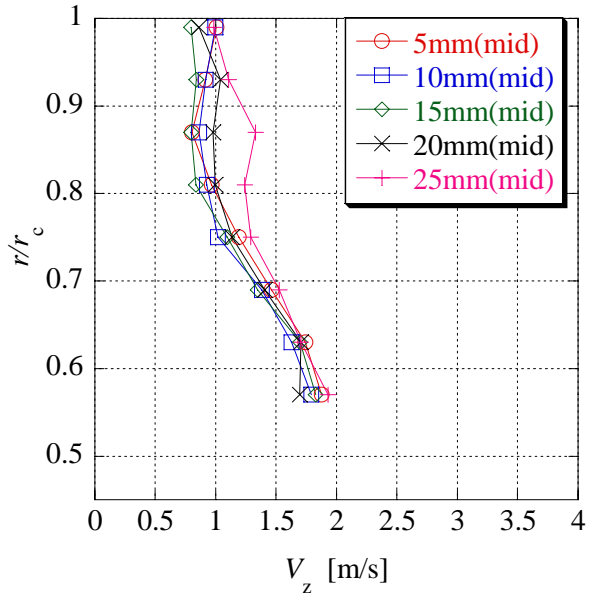

(a) Axial velocity distributions

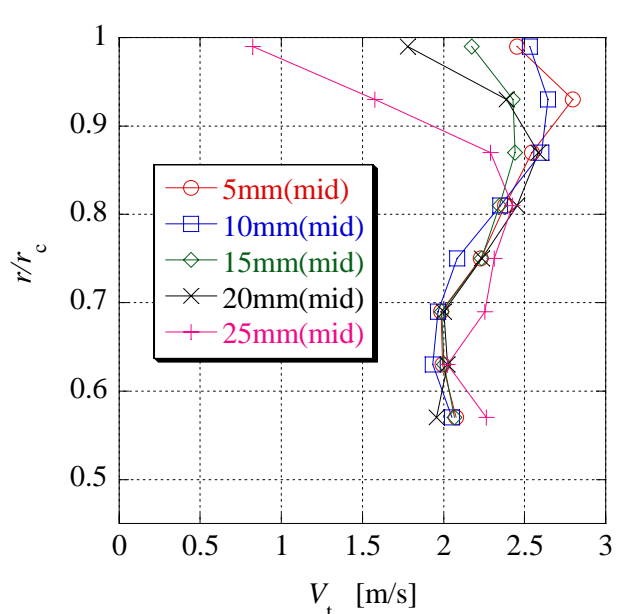

(b) Circumferential velocity distributions

Fig. 9 Velocity distributions between front and rear rotors of RRtype $\left(Q=0.0096 \mathrm{~m}^{3} / \mathrm{s}\right)$

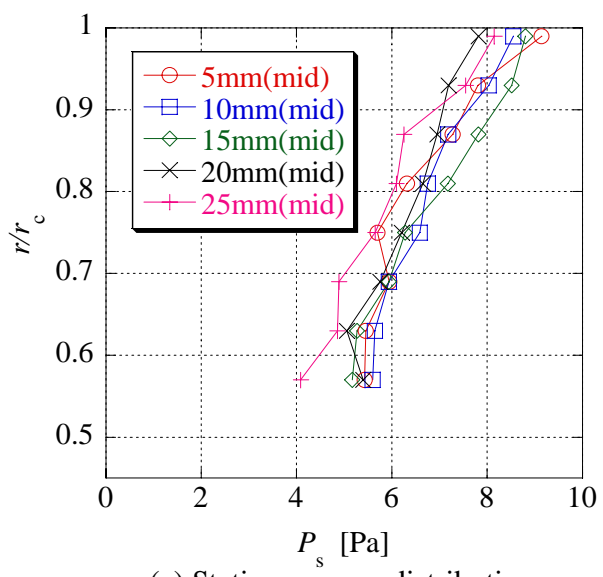

(a) Static pressure distributions

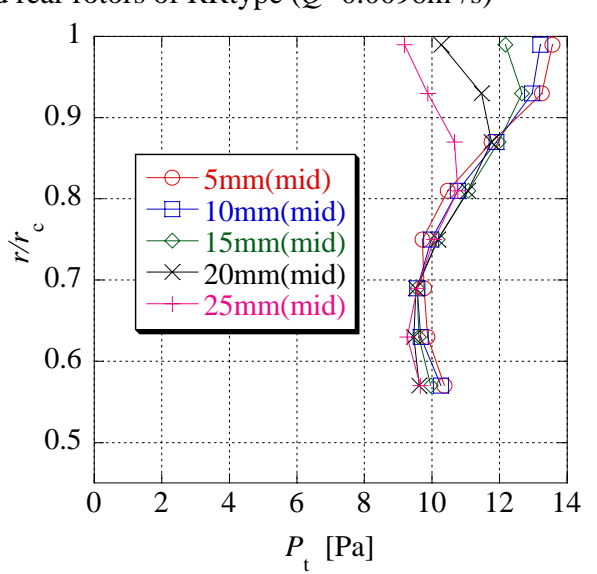

(b) Total pressure distributions

Fig. 10 Static and total pressure distributions between front and rear rotors of RRtyp $\left(Q=0.0096 \mathrm{~m}^{3} / \mathrm{s}\right)$ 


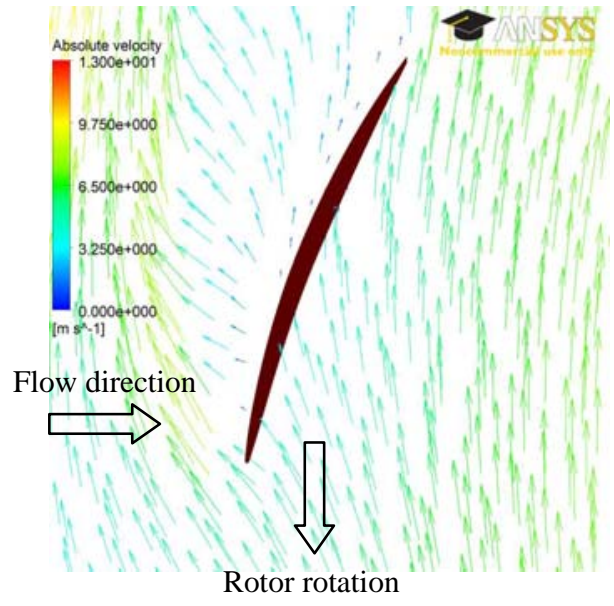

Fig. 11 Relative velocity vectors around the rear rotor of RRtype $\left(r / r_{\mathrm{c}}=0.98, Q=0.0096 \mathrm{~m}^{3} / \mathrm{s}\right)$

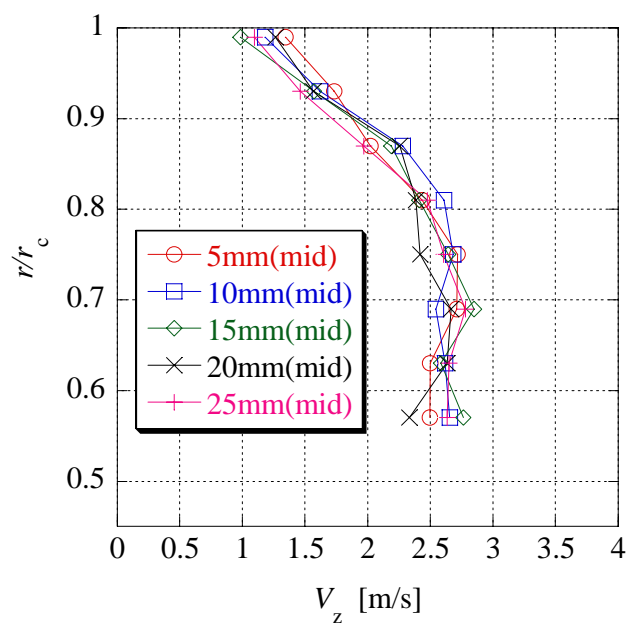

(a) Axial velocity distributions

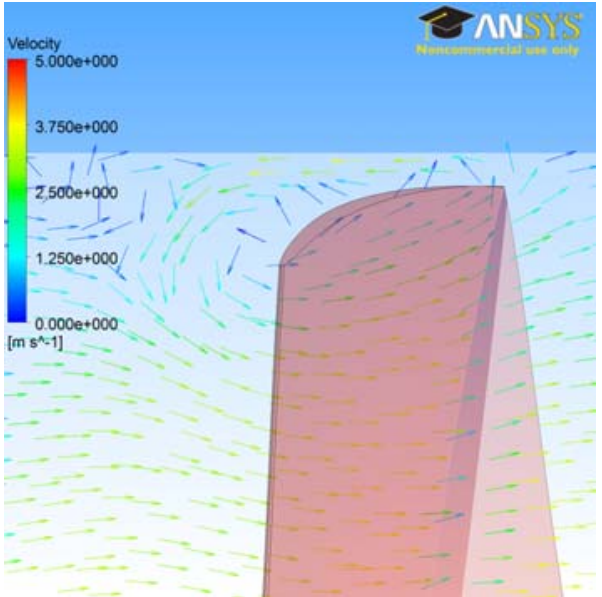

Fig. 12 Meridional velocity vectors near the tip of the rear rotor of RRtype $\left(Q=0.0096 \mathrm{~m}^{3} / \mathrm{s}\right)$

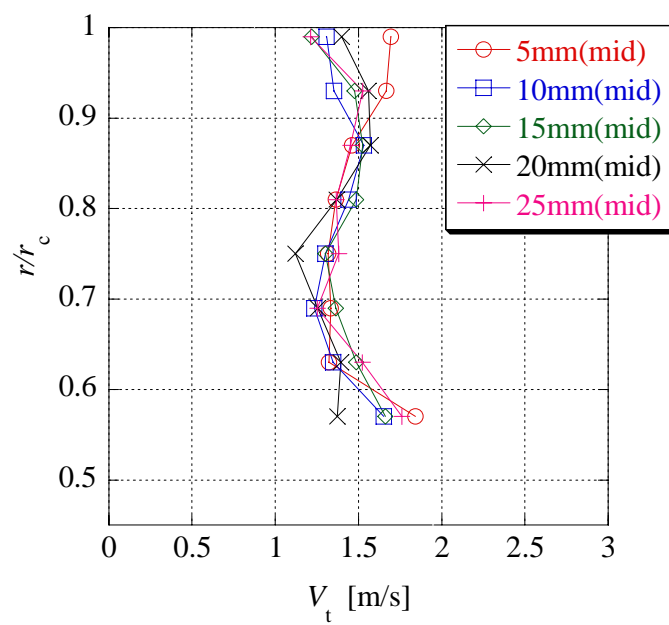

(b) Circumferential velocity distributions

Fig. 13 Velocity distributions between front and the rear rotors of RRtype $\left(Q_{\mathrm{d}}=0.016 \mathrm{~m}^{3} / \mathrm{s}\right)$

flow rate $Q_{\mathrm{d}}=0.016 \mathrm{~m}^{3} / \mathrm{s}$ respectively. The axial velocity at $Q=0.0096 \mathrm{~m}^{3} / \mathrm{s}$ in Fig.9(a) was smaller than that at $Q_{\mathrm{d}}=0.016 \mathrm{~m}^{3} / \mathrm{s}$ in Fig.13(a) and the circumferential velocity at $Q=0.0096 \mathrm{~m}^{3} / \mathrm{s}$ in Fig.9(b) was larger than that at $Q_{\mathrm{d}}=0.016 \mathrm{~m}^{3} / \mathrm{s}$ in Fig.13(b). A separation on the suction surface of the rear rotor would become large at partial flow rate due to the decrease of the axial velocity and the increase of the circumferential velocity compared to that at designed flow rate. The separation could cause a fluid loss and it was considered that rear rotor performance deteriorated by it. Therefore, it was important to suppress the back flow at the inlet of the rear rotor tip and to make uniform circumferential velocity distributions at the outlet of the front rotor to suppress excessive fluid loss with a separation even at the partial flow rate.

\subsection{Flow Conditions at The Outlet of The Rear Rotor}

Figures 14(a) and (b) show the axial and the circumferential velocity distributions of RRtype obtained by the experiment at the outlet of the rear rotor at the partial flow rate $Q=0.0096 \mathrm{~m}^{3} / \mathrm{s}$ respectively. Values in a legend are distances of the measurement positions from the rear rotor trailing edge at the hub. The axial velocity decreased $r / r_{\mathrm{c}}>0.7$ at the outlet of the rear rotor and larger non-uniformity of the axial velocity than that between front and rear rotors in Fig.9(a) was observed. This would be also caused by the flow condition inclined against hub side at the outlet of the front rotor in addition to the blockage effect by the back flow at the inlet of the rear rotor tip in Fig.12. On the other hand, the circumferential velocity was negative $r / r_{\mathrm{c}}>0.7$ at $6 \mathrm{~mm}$ downstream of the rear rotor hub for RRtype and the rear rotor gave a extra swirl flow. The mass flow rate averaged total $\left(P_{\mathrm{t}}\right)$, static $\left(P_{\mathrm{s}}\right)$ and dynamic pressure $\left(P_{\mathrm{d}}\right)$ distributions at $Q=0.0096 \mathrm{~m}^{3} / \mathrm{s}$ in axial direction of RRtype are shown in Fig.15. The horizontal axis of Fig.15 shows the axial distance from the leading edge of the front rotor at the hub. Focused on the dynamic and static pressure at the outlet of the rear rotor, the dynamic pressure decreased by $P_{\mathrm{d}}=0.80$ Pa from $z=77.5 \mathrm{~mm}$ to $z=111.5 \mathrm{~mm}$ and the static pressure 


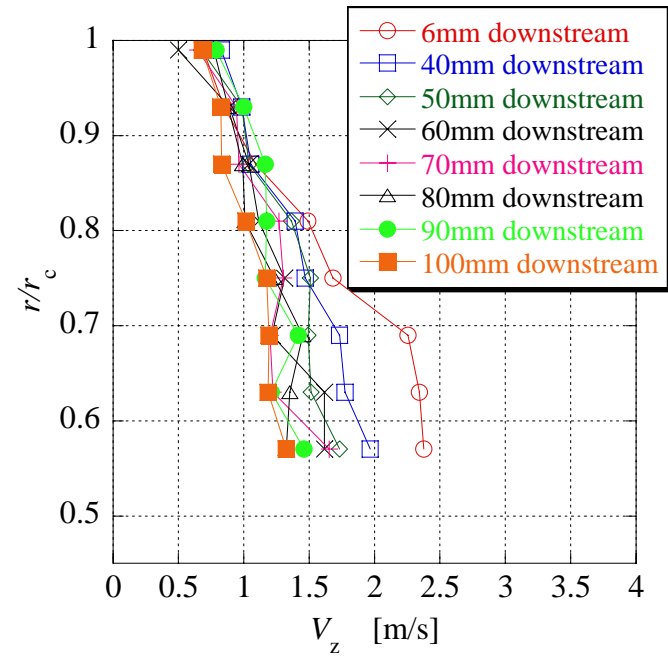

(a) Axial velocity distributions

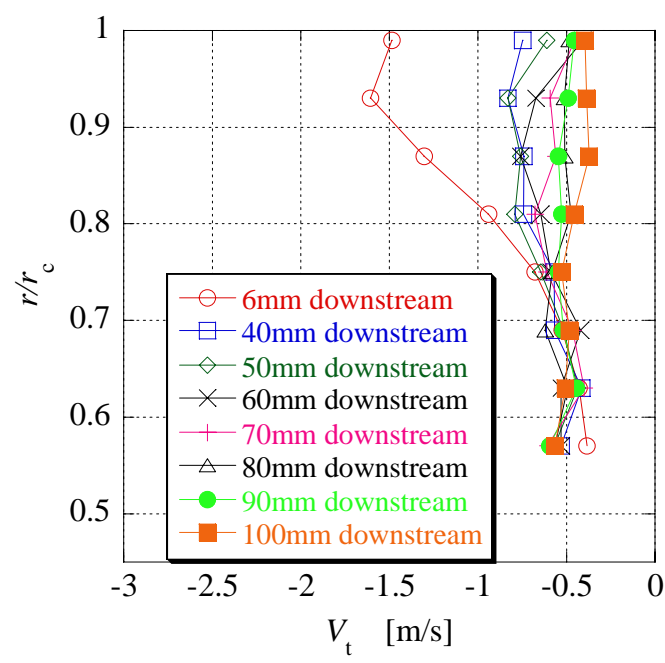

(b) Circumferential velocity distributions

Fig. 14 Velocity distributions at the rear rotor outlet of RRtype $\left(Q=0.0096 \mathrm{~m}^{3} / \mathrm{s}\right)$

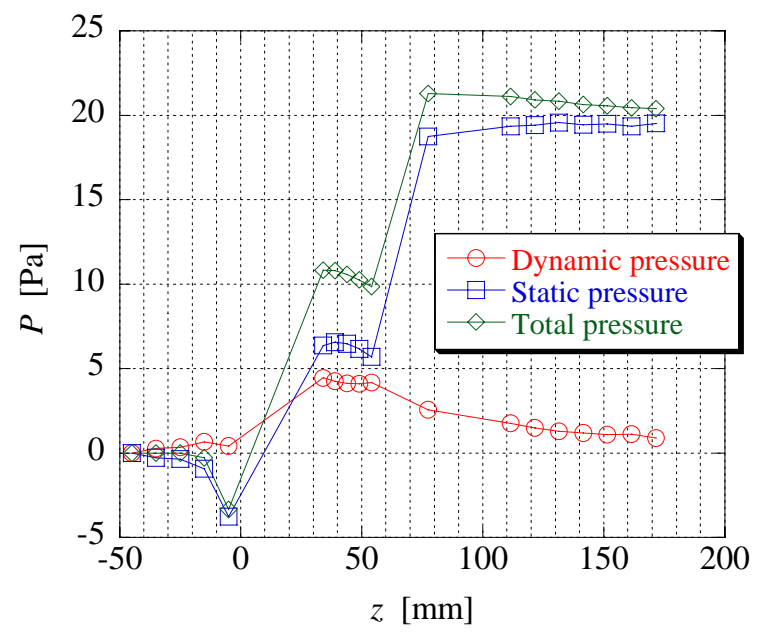

Fig. 15 Axial distributions of each pressure increase $\left(Q=0.0096 \mathrm{~m}^{3} / \mathrm{s}\right)$

recovered by $P_{\mathrm{s}}=0.61 \mathrm{~Pa}$ from $\mathrm{z}=77.5 \mathrm{~mm}$ to $\mathrm{z}=111.5 \mathrm{~mm}$. All the dynamic pressure could not recovered to the static pressure at the outlet of the rear rotor. The circumferential velocity at the outlet of the rear rotor in Fig.14(b) would be the loss at the outlet of the rear rotor. This could be one of the reasons of the performance decrease of RRtype at partial flow rate. Therefore, it would be effective to control the rear rotor rotational speed to suppress the swirl flow at the outlet of the rear rotor at partial flow rates.

\section{Conclusions}

The performance and the internal flow conditions at the partial flow rate of the contra-rotating small-sized axial fan were investigated by the experiment and the numerical analysis. As a result, following concluding remarks were obtained.

1) Although the decrements of the fan static pressure at partial flow rate which was caused by the rear rotor characteristics, the fan static pressure curve of the tested contra-rotating small-sized axial fan with $100 \mathrm{~mm}$ diameter showed the stable gentle slope.

2) At partial flow rate, the back flow occurred at the inlet tip of each front and rear rotor. And the flow inclined against hub side by the blockage effect of the back flow.

3) The rear rotor upstream flow condition was not good because of the increase of circumferential velocity and the decrease of the axial velocity at the outlet of the front rotor at partial flow rate. Further, the rear rotor gave swirl flow at the outlet of the rear rotor and this swirl flow fully could not be recovered to static pressure at partial flow rate. The rear rotor performance could be deteriorated by these influences. 


\section{Acknowledgments}

The authors wish to show our special thanks to the supports by the Komiya research aid, the project research aid from The University of Tokushima and Japan Science and Technology Agency.

\section{Nomenclature}

\begin{tabular}{|c|c|c|c|}
\hline$D_{\mathrm{h}}$ & Hub diameter $[\mathrm{m}]$ & $Q$ & Flow rate $\left[\mathrm{m}^{3} / \mathrm{s}\right]$ \\
\hline$D_{\mathrm{t}}$ & Tip diameter $[\mathrm{m}]$ & $Q_{\mathrm{d}}$ & Designed flow rate $\left[\mathrm{m}^{3} / \mathrm{s}\right]$ \\
\hline$L$ & Shaft power [W] & $R$ & Radius [m] \\
\hline$N$ & Rotational speed $\left[\mathrm{min}^{-1}\right]$ & $r_{\mathrm{c}}$ & Radius at the casing [m] \\
\hline$N_{\mathrm{f}}$ & Rotational speed of the front rotor $\left[\mathrm{min}^{-1}\right]$ & $U$ & Circumferential speed of the rotor $=\pi D_{\mathrm{t}} N / 60[\mathrm{~m} / \mathrm{s}]$ \\
\hline$N_{\mathrm{r}}$ & Rotational speed of the rear rotor $\left[\mathrm{min}^{-1}\right]$ & $U_{R R}$ & Circumferential speed of the rotor for RRtype \\
\hline$P_{\mathrm{d}}$ & Dynamic pressure[Pa] & & $=\pi D_{\mathrm{t}} N_{r} / 60[\mathrm{~m} / \mathrm{s}]$ \\
\hline$P_{\mathrm{s}}$ & Static pressure $[\mathrm{Pa}]$ & $V_{\mathrm{t}}$ & Circumferential component of absolute velocity \\
\hline$P_{\mathrm{t}}$ & Total pressure $[\mathrm{Pa}]$ & & {$[\mathrm{m} / \mathrm{s}]$} \\
\hline$\Delta P$ & Fan static pressure $[\mathrm{Pa}]$ & $V_{\mathrm{z}}$ & Axial component of absolute velocity [m/s] \\
\hline$\Delta P_{\mathrm{dR}}$ & Designed fan static pressure of conventional & $Z$ & Axial distance $[\mathrm{m}]$ \\
\hline & small-sized axial fan [Pa] & $\rho$ & Density of air $\left[\mathrm{kg} / \mathrm{m}^{3}\right]$ \\
\hline$\Delta P_{\mathrm{dRR}}$ & $\begin{array}{l}\text { Designed fan static pressure of contra-rotating } \\
\text { small-sized axial fan }[\mathrm{Pa}]\end{array}$ & $\eta$ & Static pressure efficiency $=\Delta P Q / L$ \\
\hline
\end{tabular}

\section{References}

[1] Miyahara, M and Fukano, T., 2006., “Fan Cooling Technology for Small Electronic Device,” Turbomachinery(in Japanese), Vol. 34, No. 3, pp. 129-134.

[2] Furukawa, A., Shigemitsu, T and Watanabe, S., 2007., "Performance Test and Flow Measurement of Contra-Rotating Axial Flow Pump,” J. Thermal Science, Vol. 16, No. 1, pp. 7-13.

[3] Furukawa, A., Cao, Y., Okuma, K and Watanabe, S., 2000., "Experimental Study of Pump Characteristics of Contra-Rotating Axial Flow Pump,” Proc. 2nd Int. Symp. on Fluid Machinery and Fluid Eng., Beijing, 67-657, pp. $245-252$.

[4] Kodama, Y., Hayashi, H., Fukano, T and Tanaka, K., 1994., "Experimental Study on the Characteristics of Fluid Dynamics and Noise of a Counter-Rotating Fan(1st Report, Effects of the Supporter Shape of the Electric Motor and the Distance between Two Rotors on the Characteristics),” Trans. JSME (in Japanese), Vol. 60, No. 576, pp. 2764-2771.

[5] Shigemitsu, T., Furukawa, A., Okuma, K and Watanabe, S., 2002., "Experimental Study on Rear Rotor Design in ContraRotating Axial Flow Pump,” Proc. 5th JSME/KSME Fluids Eng. Conf., Nagoya, (2002), pp. 1453-1548.

[6] Sanders, A, J., Papalia, J and Fleeter, S., 2002., "Multi-Blade Row Interactions in a Transonic Axial Compressor: Part I- Stator Particle Image Velocimetry (PIV) Investigation,” ASME J. Turbomachinery, Vol. 124, pp. 10-18.

[7] Shigemitsu, T., Fukutomi, J and Okabe, Y., 2010., "Performance and Flow Condition of Small-Sized Axial Fan and Adoption of Contra-Rotating Rotors,” J. Thermal Science., Vol. 19, No. 1, pp.1-6.

[8] Ito, T., Minorikawa, G. Nagamatsu, A and Suzuki, S., 2006., "Experimental Research for Performance and Noise of Small Axial Flow Fan(influence of Parameter of Blade),” Trans. JSME (in Japanese), Vol. 72, No. 715, pp. 670-677. 